SISTEMA
ELETRONIICO
DE REVISTAS
SER I UFPR

\title{
Análise da cobertura e uso da terra da bacia hidrográfica do Rio do Coco e suas implicações sobre as áreas de preservação permanente como instrumento na gestão dos recursos hídricos
}

\section{Analysis of land use and cover in the hydrographic basin of the Coco River and its implications on Permanent Preservation Areas as a tool in water resources management}

\author{
Rejane Freitas Benevides ALMEIDA ${ }^{1 *}$, Laerte Guimarães FERREIRA JÚNIOR ${ }^{2}$, Maximiliano BAYER ${ }^{2}$ \\ ${ }^{1}$ Instituto Federal do Tocantins (IFTO), Paraíso do Tocantins, TO, Brasil. \\ ${ }^{2}$ Universidade Federal de Goiás (UFG), Goiânia, GO, Brasil. \\ *E-mail de contato: rejane@ifto.edu.br
}

Artigo recebido em 30 de março de 2018, versão final aceita em 21 de agosto de 2018.

RESUMO: Estudos voltados ao diagnóstico das áreas de preservação permanente (APPs) em relação ao atendimento da legislação são importantes instrumentos para a gestão dos recursos hídricos. Desse modo, o presente trabalho teve como objetivo avaliar a cobertura, o uso da terra e os conflitos de uso nas áreas de preservação permanente de cursos d'água na bacia do Rio do Coco, localizada na margem direita da bacia hidrográfica do Rio Araguaia, no estado do Tocantins. Para tanto, realizou-se o mapeamento da cobertura e uso do solo da bacia, utilizando imagens do satélite Landsat 8 (sensor OLI - Operational Land Imager) para o ano de 2015. Para a delimitação das APPs, realizou-se inicialmente a vetorização manual da rede de drenagem na escala 1: 5.000, utilizando imagens do satélite RapidEye. De posse da hidrografia, foram criados buffers de APPs, os quais obedeceram às faixas de proteção definidas pela legislação para cada curso d'água. Os conflitos de uso do solo foram obtidos por meio da sobreposição do mapa gerado com a classificação da imagem e o mapa de APP. Os resultados da pesquisa indicaram que a bacia do Rio do Coco apresenta 56,91\% de sua área total coberta por atividades antrópicas, com um déficit de 32,8\% de APP, sendo a pastagem o uso dominante. As sub-bacias do Alto Rio do Coco, Ribeirão Piedade e Ribeirão Surubim apresentaram os maiores percentuais de conflitos, comparados as demais bacias analisadas, com 46,03\%, 40,1\% e 39,35\%, respectivamente. Por fim, a partir do estudo foi possível compreender a distribuição dos usos em toda a bacia, seus conflitos e suas possíveis consequências sobre as áreas legalmente protegidas, podendo ser uma ferramenta eficaz nas 
tomadas de decisão para investimentos nas ações de conservação da bacia hidrográfica do Rio do Coco.

Palavras-chave: cobertura e uso do solo; conflitos de uso do solo; Bacia do Rio do Coco.

ABSTRACT: Studies focused on the diagnosis of the permanent preservation areas (PPAs) in relation to the attendance of the legislation are important for the management of the water resources. In this way, the present work was aimed at the evaluation of the coverage, land use and conflicts of use in the areas of permanent preservation (PPAs) of watercourses in the Coco River basin, located on the right bank of the Araguaia River basin in the state of Tocantins. To do so, the basin's land cover and use was mapped using images from Landsat 8 (OLI Operational Land Imager) satellite for the year 2015. For the delimitation of the PPAs, the drainage network was manually vectorized in the 1: 5000 scale, using images from the RapidEye satellite. In possession of the hydrography, PPA buffers were created, which obeyed the protection ranges defined by the legislation for each watercourse. Land use conflicts were obtained by overlapping the generated map with the image classification and PPA map. The results of the research indicated that the Coco River basin presents $56.91 \%$ of its total area covered by anthropic activities, with a deficit of $32.8 \%$ of PPA, with pasture being the dominant use. The Upper Coco River, Ribeirão Piedade and Ribeirão Surubim sub-basins presented the highest percentage of conflict, compared to the other analyzed basins, with $46.03 \%, 40.1 \%$ and $39.35 \%$, respectively. Finally, it was possible to understand, from the study, the distribution of uses throughout the basin, their conflicts and its possible consequences on legally protected areas, can be an effective tool in decision making for investments in conservation actions in the Rio do Coco river basin.

Keywords: coverage and land use; conflicts of land use; Basin of the Coco River.

\section{Introdução}

A degradação ambiental encontra-se fortemente ligada à maneira como o homem tem ocupado e utilizado a terra, de forma impensada e predatória, modificando severamente a paisagem original e gerando sérios danos ao meio ambiente (Silva et al., 2014).

Campos et al. (2013) consideram como catalisador do problema o atual modelo socioeconômico de desenvolvimento adotado no país, o qual apresenta permanente conflito com o ambiente devido à ausência, em muitas vezes, de uma ocupação planejada. Para os autores, o conhecimento das áreas de uso de uma determinada região, além de possibilitar o direcionamento adequado do tipo de manejo, permite identificar possíveis problemas acarretados pelo efeito das ações antrópicas sobre essas regiões, tendo relação direta com a conservação e a exploração sustentável dos recursos naturais. Dentro dessa abordagem de degradação da paisagem, a bacia hidrográfica surge como elemento chave para uma análise mais apropriada. Conforme é ressaltado por Zanata et al. (2015), a bacia é um sistema aberto, onde o fluxo de matéria e energia é dinâmico e altamente dependente da gestão dos solos.

O manejo das bacias, em função do uso e ocupação do solo, associado às suas características, pode interferir significativamente em todo o sistema (Aparecido et al., 2016). Mudanças em grande escala podem alterar os padrões de clima e precipitação locais, intensificando o escoamento superficial com consequente aumento nos processos erosivos (Gurnell et al., 2014). Assim, Vargas et al. 
(2015) descrevem que em uma análise geoambiental integrada de qualquer bacia hidrográfica é necessário pesar os impactos dos diferentes usos da terra sobre a dinâmica de toda a região.

Em face disso, o planejamento adequado da terra deve ser realizado constantemente para que a degradação não ocorra ou, ao menos, seja diminuída ao longo da bacia, principalmente nas áreas de preservação permanente (Campos et al., 2013), pois estas são uns dos componentes da natureza que mais influenciam no funcionamento do sistema, tendo como função, a proteção do solo e da qualidade da água (Rodrigues et al., 2015b). Além disso, tais áreas apresentam funções de estabilização, fonte de matéria e energia, refúgio de vida silvestre, filtro de nutrientes, controlador de temperatura e produtividade da água, além de servir de conexão entre paisagens e proteção contra a erosão, entre outros (Romero et al., 2014).

Há que se destacar, portanto, que a vegetação ao longo dos rios possui um papel fundamental na gestão dos recursos hídricos de toda a bacia, entretanto, se observa ainda pouca atenção dada às mesmas, principalmente no que diz respeito a sua proteção conforme definido em legislação.

Estudos mostram a existência de conflitos de uso significativos em relação a estas regiões. Tal situação é agravada pelas ações ilegais de desrespeito ao Código Florestal brasileiro, no que concerne à manutenção da floresta natural ao longo dos rios e nascentes, como também a falta de fiscalização e dificuldades na recuperação destas áreas (Almeida \& Vieira, 2014).

Diante deste cenário, a bacia hidrográfica do Rio do Coco surge como objeto de estudo, uma vez que a mesma apresenta padrões diferenciados de cobertura e uso do solo, os quais têm sido alterados pela chegada da agricultura na região, especificamente o cultivo de soja.

Atualmente são muitas as ferramentas para estudos de uso e ocupação do solo; entretanto, o geoprocessamento se destaca, uma vez que permite analisar grandes áreas, possibilitando uma melhor compreensão da dinâmica da paisagem em diferentes escalas espaço temporais (Pereira et al., 2014). Nessa perspectiva, pretende-se analisar a distribuição da cobertura e uso do solo da bacia hidrográfica do Rio do Coco como um todo, com o objetivo de identificar e quantificar os conflitos de uso do solo existentes para as áreas de preservação permanente de cursos d'água, conforme os parâmetros de proteção estabelecidos na legislação ambiental (Lei 12.651/2012), utilizando o geoprocessamento como ferramenta de análise.

\section{2. Área de Estudo}

A área de estudo compreende a bacia hidrográfica do Rio do Coco, localizada na margem direita da média bacia do Rio Araguaia (Aquino et al., 2005) no Estado do Tocantins (Figura 1). Esta ocupa uma área de aproximadamente $6.670 \mathrm{~km}^{2}$, distribuídos entre os municípios de Caseara, Marianópolis do Tocantins, Divinópolis do Tocantins, Monte Santo, Paraíso do Tocantins, Chapada de Areia, Pium e Barrolândia. O principal curso d'água da bacia é o Rio do Coco, com extensão aproximada de $356 \mathrm{~km}$, estando suas nascentes principais localizadas na Serra do Estrondo e foz no município de Caseara. 


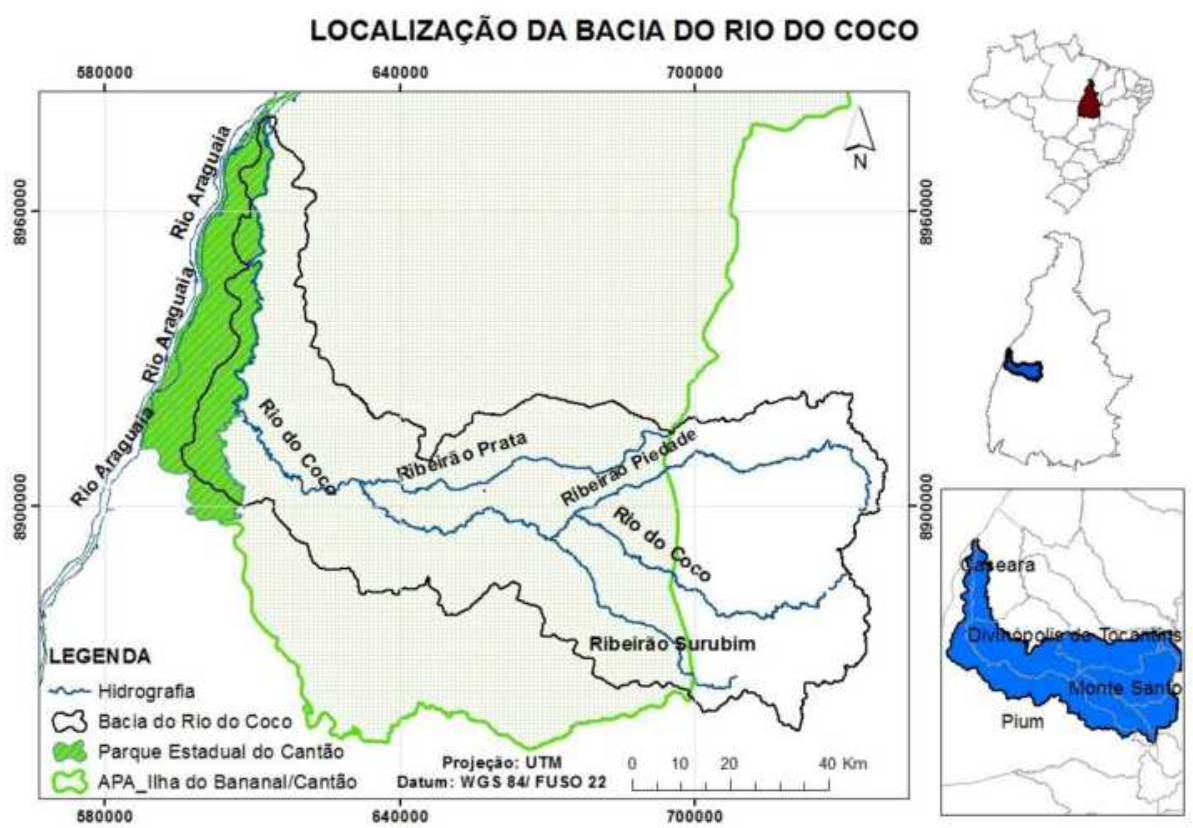

FIGURA 1 - Localização da bacia do Rio do Coco no estado do Tocantins, Brasil, com destaque para os principais cursos d'água existentes, bem como para as unidades de conservação inseridas nos limites da bacia.

FONTE: Elaborado pelo autor.

Destaca-se que aproximadamente $67,7 \%$ da área da bacia está inserida em unidades de conservação, sendo 5,5\% no Parque Estadual do Cantão e $61,2 \%$ na APA Ilha do Bananal/Cantão. O Parque do Cantão forma uma grande planície aluvial, composta, principalmente, por areias de quartzo e sedimentos depositados pelos rios Javaé e Araguaia. A planície é coberta, em sua maioria, por uma floresta pluvial, pertencente ao domínio amazônico, com mais de 840 lagos, $150 \mathrm{~km}$ de meandros e canais naturais, assim como também por um tipo de cerrado localmente conhecido como "varjão", que é periodicamente inundado (Ferreira et al., 2011). Face às peculiaridades citadas e por se tratar de uma unidade de conservação de proteção integral, a área que abrange o Parque Estadual do Cantão inserida nos limites da bacia do Rio do Coco foi excluída desta análise. Dessa forma, a área analisada conta com aproximadamente $6.311,36 \mathrm{~km}^{2}$.

\section{Procedimentos metodológicos}

Os procedimentos metodológicos para o desenvolvimento do trabalho foram divididos em três etapas: obtenção de dados e classificação de imagens; delimitação das áreas de preservação permanente de cursos d'água; análise da cobertura e uso da terra e conflitos de uso em APP, conforme demonstrado no organograma dos procedimentos metodológicos contidos na Figura 2. 


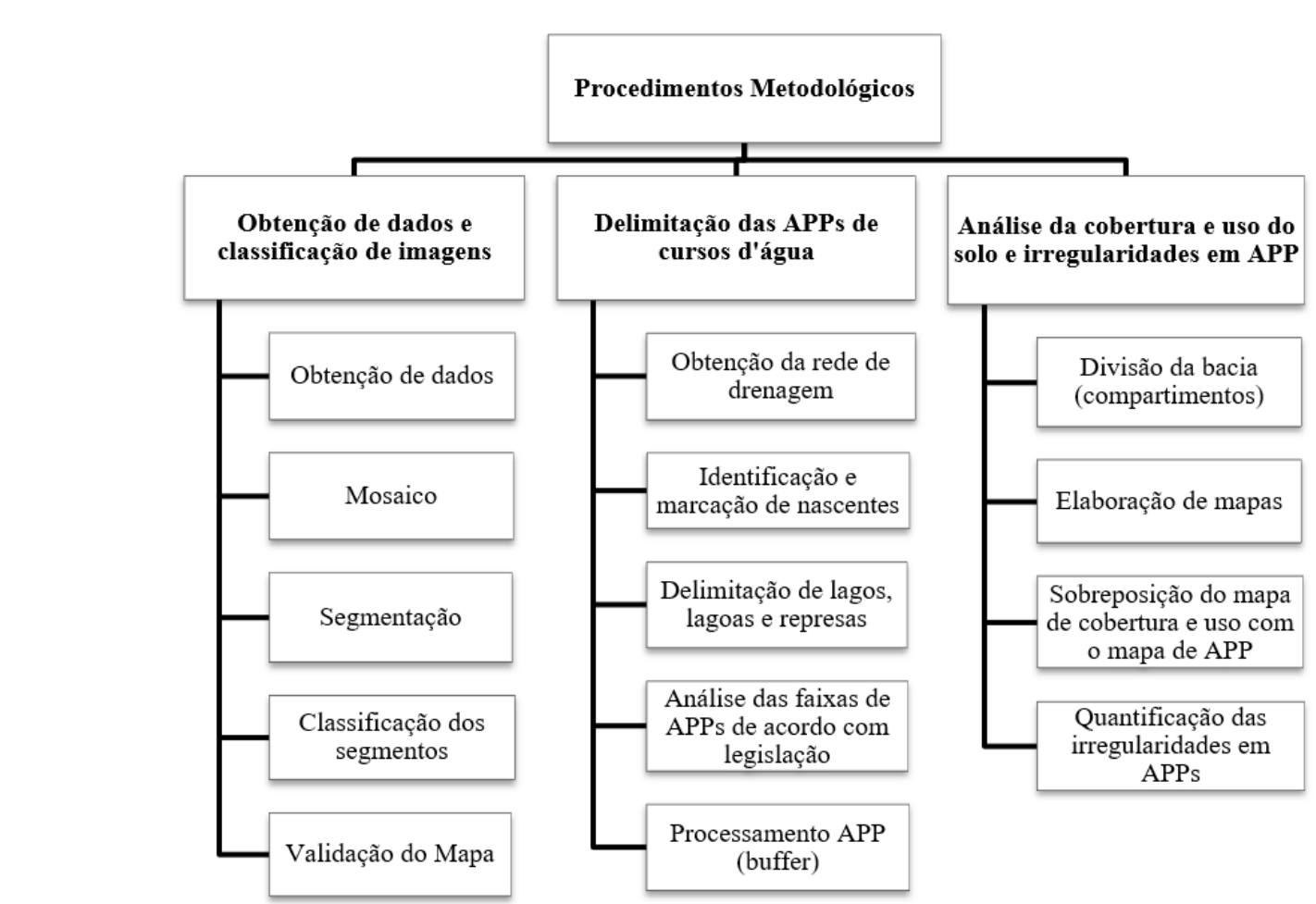

FIGURA 2 - Organograma esquemático dos procedimentos metodológicos utilizados na pesquisa.

\subsection{Obtenção de dados e classificação de imagens}

O mapeamento da cobertura e uso da terra foi realizado utilizando imagens do satélite Landsat 8 (sensor OLI - Operational Land Imager) selecionadas no catálogo de imagens do Instituto de Pesquisas Espaciais (INPE - http://www.dgi.inpe. br). Para o recobrimento total da área de estudo foram utilizadas as cenas 222/67 e 223/67 (órbita/ ponto), as quais foram registradas para o fuso UTM 22S, Datum WGS 1984. As imagens são datadas de agosto de 2015, tendo sido esta escolha feita em virtude da qualidade apresentada em relação à baixa incidência de nuvens.
Inicialmente, realizou-se o mosaico das cenas utilizadas, sendo logo em seguida realizado o recorte da área a ser classificada. De posse do recorte aplicou-se a segmentação da imagem. Tal processo foi realizado no ENVI a partir da ferramenta Feature extraction. Os parâmetros adotados foram: segmentação pelo algoritmo Edge com nível de escala 60 e merge pelo algoritmo Full Lambda Schedule com nível 90 e textura tipo Kernel, tamanho 3. Após a segmentação foi elaborada uma máscara para separar as áreas de vegetação das demais áreas com base no NDVI. Este índice varia de - 1 a 1 e constitui um bom separador de áreas com biomassa fotossinteticamente ativa, estando áreas com maior proporção de biomassa mais próximas de 1 e áreas 
com menor proporção de biomassa, mais próximas de -1, conforme Rouse et al. (1973). A finalidade desse procedimento foi aplicar parâmetros distintos de segmentação e fusão para as regiões criadas, uma vez que estas apresentam padrões diferentes. O resultado foi exportado para o formato shapefile e, posteriormente, criada as máscaras de vegetação e de não vegetação (antrópico).

O objetivo das máscaras foi auxiliar o processo de classificação dos segmentos, a partir da separação das áreas com vegetação das demais áreas, facilitando a análise da cobertura e uso da bacia. Vale ressaltar que a classe de vegetação, separada previamente, foi também classificada de acordo com as classes estabelecidas para a cobertura vegetal definidas neste trabalho (Tabela 1). A classificação de todos os segmentos gerados foi realizada a partir da inspeção visual de imagens do Landsat 8 utilizadas durante $o$ processo de classificação. Para uma melhor distinção entre as classes, o procedimento de classificação considerou imagens dos períodos seco (agosto) e chuvoso (abril), com vistas a avaliar os efeitos da sazonalidade sobre os diferentes alvos, obtendo assim uma melhor compreensão das classes analisadas.

Durante o processo de inspeção visual foram utilizados como apoio as imagens provenientes da plataforma Google Earth e imagens RapidEye de 2013 (resolução espacial de $5 \mathrm{~m}$ ), além de comparações com a base de dados dos mapeamentos de uso da terra e cobertura vegetal remanescente do Estado do Tocantins/ano base 2007 e Projeto TerraClass Cerrado/ano base 2013.

A escala de visualização (zoom) utilizada foi de 1:20.000. Entretanto, no caso de incertezas, a escala adotada foi ajustada para a obtenção de detalhe, com vistas a melhorar a distinção da classe e a percepção do padrão de cobertura e uso do solo no entorno da área analisada.

TABELA 1 - Classes de cobertura e uso da terra e suas respectivas características utilizadas como referência durante a classificação de imagens.

\begin{tabular}{ll}
\hline \multicolumn{1}{c}{ Classes } & \multicolumn{1}{c}{ Características } \\
\hline Áreas antrópicas & Agricultura ciclo longo e curto \\
\hline Agricultura & Área urbana \\
Área urbana & Reflorestamento e silvicultura \\
Floresta Plantada & Rodovias pavimentadas e não pavimentadas \\
Estradas & Assentamentos, vilas, povoados \\
Mosaicos de ocupação & Pastagem intensiva, semi-intensiva e extensiva \\
Pastagem & \\
\hline Áreas naturais & Cerrado ralo e rupestre, parque cerrado, campo sujo e varjão \\
\hline Cerrado Sentido Restrito Ralo & Cerrado denso e típico \\
Cerrado Sentido Restrito Denso & Rios, córregos, lagos, lagoas, represas \\
Corpos d'água & Floresta estacional, mata ciliar, mata de galeria, mata seca e cerradão \\
Formações Florestais & Praias \\
Praias & \\
\hline
\end{tabular}


Com o intuito de avaliar a concordância entre o mapa classificado e a realidade local, foram realizadas coletas de pontos com GPS de navegação ao longo de toda a bacia. No total, foram coletados 272 pontos em campo durante duas campanhas executadas nos meses de junho e agosto de 2016. Priorizou-se, em campo, visitar as classes que geraram maiores dúvidas durante a classificação. Os pontos coletados, posteriormente, foram utilizados no cálculo da exatidão global a partir de uma matriz de confusão, obtendo-se dessa forma uma estimativa de exatidão da classificação, conforme Congalton (2005).

A avaliação da precisão começa com a geração de uma matriz de erros, uma matriz quadrada de números ou células dispostas em linhas e colunas, que expressa o número de unidades de amostras atribuídas a cada tipo de cobertura de terra em com- paração com os dados de referência. As colunas da matriz representam os dados de referência (dados de campo) e as linhas representam tipos de cobertura de terra atribuídos (mapeados). A grande diagonal da matriz indica concordância entre os dados de referência e os tipos de cobertura de terra interpretados (Congalton, 2005). Por fim, os resultados da matriz de confusão indicam a concordância entre o mapa obtido na classificação e a realidade de campo.

\subsection{Delimitação das áreas de preservação permanente de cursos d'água}

A Figura 3 apresenta um resumo esquemático dos passos executados para a obtenção das áreas de preservação permanente de cursos d'água.

Para a delimitação das áreas de preservação permanente de cursos d'água, inicialmente, foi

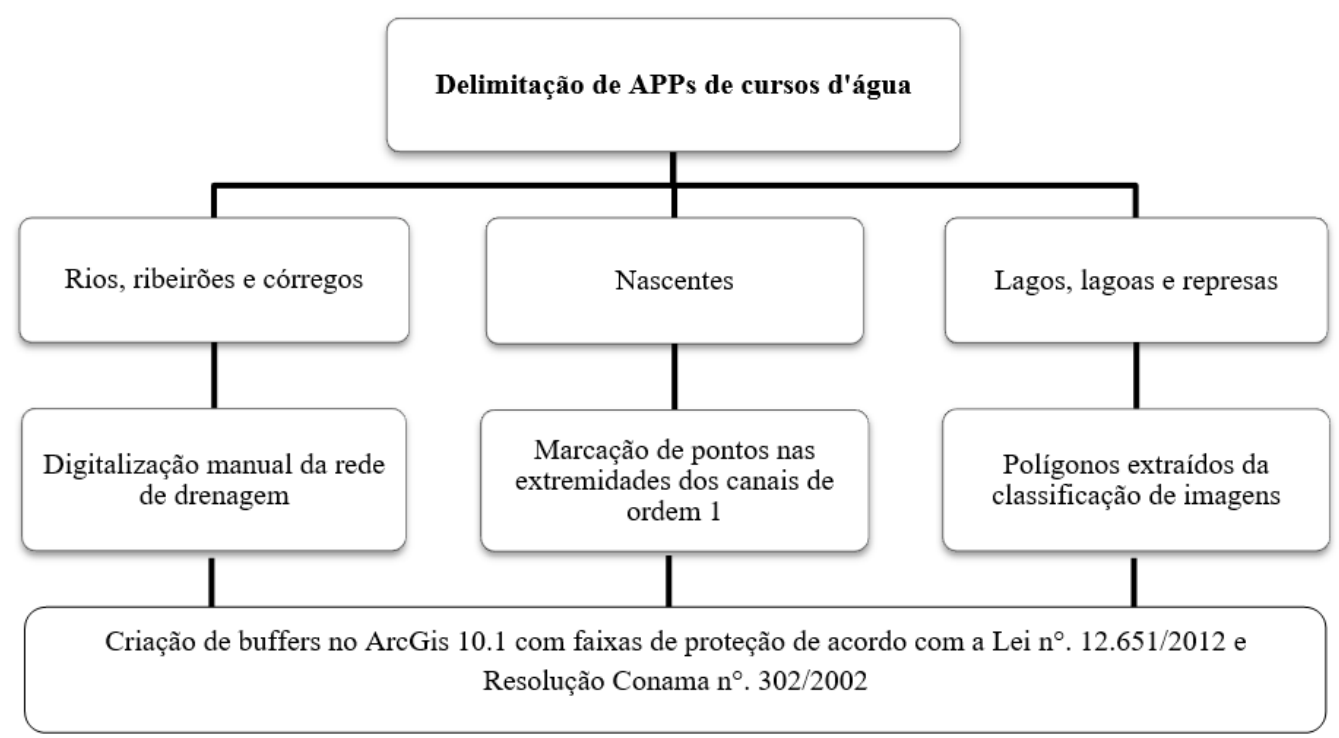

FIGURA 3 - Resumo esquemático dos passos executados para a delimitação das Áreas de Preservação Permanente (APP) de cursos d'água presentes na Bacia do Rio do Coco, Tocantins, Brasil. 
necessária a definição da rede de drenagem a ser utilizada. Tal procedimento é realizado comumente de forma automática, utilizando o modelo digital de elevação (MDE), porém, após a realização de testes com o MDE observaram-se inúmeras inconsistências nos dados executados, fato que poderia resultar em incoerências nas informações sobre as APPs. Assim, com vistas a produzir uma rede hidrográfica de boa qualidade optou-se pela vetorização manual da hidrografia na escala 1:5.000, a partir de imagens do satélite RapidEye (2011).

As nascentes foram obtidas por meio da marcação de pontos nas extremidades de todos os canais de ordem 1, definidos por meio da hierarquização da rede de drenagem, conforme classificação de Strahler (1952). Já os lagos, as lagoas e as represas foram extraídas da classificação de imagens, sendo considerados apenas os polígonos acima de um hectare.

Para a delimitação das APPs foram considerados todos os cursos d'água presentes na bacia (rios, ribeirões, córregos, lagos, lagoas, represas e nascentes), sendo utilizados os parâmetros estabelecidos de proteção na legislação ambiental (Lei 12.651/2012) para a definição das faixas de preservação adotadas. Entretanto, não foi empregado o critério de áreas consolidadas em APPs descrito pela referida legislação, o qual autoriza a continuidade das atividades agrossilvipastoris, de ecoturismo e de turismo rural em áreas rurais consolidadas até 22 de julho de 2008, sendo permitida nestas áreas a recuperação parcial da APP de acordo com o tamanho do imóvel e não de acordo com a largura do curso d'água. Esse critério não foi avaliado devido às dificuldades na obtenção de todos os shapes dos imóveis inseridos na bacia do Rio do Coco junto aos órgãos ambientais.
É importante destacar que, para os reservatórios artificiais, a legislação atual (Lei 12.651/2012) estabelece que as faixas de preservação devam ser definidas no processo de licenciamento ambiental, no entanto, devido aos obstáculos para o acesso às informações definidas no momento da emissão das respectivas licenças utilizaram-se como parâmetros, neste trabalho, os critérios preconizados na Resolução Conama $n^{\circ}$. 302/2002, a qual trata dos limites de áreas de preservação permanente de reservatórios artificiais.

Na Tabela 2 estão descritas as áreas de preservação permanente que foram avaliadas, bem como os limites para preservação considerados, conforme Lei $12.651 / 2012$. Predominaram na bacia do Rio do Coco cursos d'água com larguras até 10 metros, sendo dessa forma 30 metros a faixa mais representativa de APP observada. Vale mencionar que as larguras dos cursos d'água foram estabelecidas a partir de observações em imagens provenientes da plataforma Google Earth, além de visitas a campo para dirimir as dúvidas geradas durante as análises.

De posse da rede hidrográfica e das informações sobre os limites das APPs a serem utilizados deu-se início ao processamento dos dados, sendo criados buffers de APPs para cada caso estudado (Tabela 2).

\subsection{Análise da cobertura e uso da terra e conflitos de uso em APP}

Essa etapa buscou compreender as principais formas de cobertura e uso da terra da bacia do Rio do Coco, analisando os efeitos das atividades existentes na degradação dos recursos naturais, principalmente, no que diz respeito às áreas de 
TABELA 2 - Limites das faixas de APPs de cursos d'água adotados no trabalho de acordo com a legislação pertinente.

\begin{tabular}{ccc}
\hline & Cursos d'água & Largura do curso d'água (m) \\
\hline Faixa de APP $(\mathbf{m})$ & $10 \mathrm{~m}$ \\
\hline $30 \mathrm{~m}$ & 10 a $50 \mathrm{~m}$ \\
\hline $100 \mathrm{~m}$ & 50 a $200 \mathrm{~m}$ \\
\hline $200 \mathrm{~m}$ & 200 a $600 \mathrm{~m}$ \\
\hline $500 \mathrm{~m}$ & Lagos e Lagoas & Urbano \\
\hline Rural & S & $30 \mathrm{~m}$ \\
\hline $100 \mathrm{~m}$ para área $>20$ ha & Reservatórios artificiais & Urbano \\
\hline $50 \mathrm{~m}$ para área até 20 ha & & $30 \mathrm{~m}$
\end{tabular}

FONTE: Adaptado de Brasil (2012) e Brasil (2002).

preservação permanente de cursos d'água. Para tanto, foram elaborados mapas de cobertura e uso da terra para a área total da bacia do Rio do Coco, todavia, a área que abrange o Parque Estadual do Cantão foi excluída desta análise por se tratar de uma Unidade de Conservação de Proteção Integral. Com o intuito de avaliar a distribuição da cobertura e uso da terra ao longo da área de estudo, bem como analisar as áreas que concentram os maiores conflitos de uso e, por conseguinte, requerem intervenções importantes no processo de gestão, também foi realizada a compartimentação da bacia do Rio do Coco em alta e baixa bacia. No compartimento da alta bacia ficaram as sub-bacias de ordem 6: Ribeirão Piedade, Ribeirão Surubim e Alto Rio do Coco, enquanto que no compartimento da baixa bacia ficaram as sub-bacias do Ribeirão Prata (ordem 5) e Baixo Rio do Coco (ordem 7).

Tendo em vista a análise dos conflitos de uso nas áreas de preservação permanente, elaboraram-se mapas de cobertura e uso da terra para as APPs de cada sub-bacia. Estes foram obtidos por meio da sobreposição do mapa gerado com a classificação da imagem e o mapa de APP. Após a sobreposição dos mapas, foram mensuradas as áreas correspondentes a cada classe, assim como os percentuais de uso em APPs por meio de cálculos de área. Vale ressaltar que os conflitos de uso considerados neste trabalho referem-se a qualquer tipo de uso antrópico identificado nos limites das áreas que deveriam ser destinadas a preservação permanente. 


\section{Resultados e discussão}

\subsection{Avaliação da acurácia da classificação}

A Tabela 3 apresenta os resultados obtidos a partir da matriz de confusão. Como pode ser observado, o produto dessa análise indica que o mapa classificado possui uma exatidão global de $92,27 \%$, obtendo a classe de Floresta Plantada o maior nível de acertos (100\%), seguida pelas classes de Agricultura (93,62\%), Cerrado Sentido Restrito Denso (93,6\%), Pastagem (91,9\%), Formações Florestais $(90,9 \%)$ e Cerrado Sentido Restrito Ralo (75\%).

Quando se analisa a acurácia do produtor, a qual avalia a probabilidade das amostras coletadas em cada classe terem sido classificadas de forma correta, observa-se que as classes de Formações Florestais e a Floresta Plantada se destacam com $100 \%$, sendo o menor acerto observado na classe de Cerrado Sentido Restrito Ralo (85,71\%). É muito comum dúvidas com relação a essa classe, pois muitas vezes pode ser confundida com a pastagem, principalmente quando há um abandono temporário da atividade agropecuária, formando áreas com presença de regenerantes da vegetação nativa (pasto sujo).

No geral, os resultados indicam que a metodologia utilizada na classificação foi considerada satisfatória, pois o mapa de cobertura e uso da terra apresentou, ao ser comparado com os 272 pontos coletados em campo, uma exatidão global de aproximadamente $92,27 \%$. Resultados semelhantes (90\%) foram encontrados por Sousa e Ferreira (2014) ao realizarem um mapeamento da cobertura e uso da terra na bacia do Ribeirão João Leite (GO) utilizando dados de campo para validação e por Prina e Trentin (2015) que ao utilizarem o ArcGis para a classificação de imagens obtiveram uma exatidão global de $96 \%$.

\subsection{Cobertura e uso da terra da bacia do Rio do Coco}

A análise da cobertura e uso da terra para a bacia hidrográfica do Rio do Coco considerou 11 classes para a classificação: Agricultura, Área urbana, Cerrado Sentido Restrito Ralo, Cerrado Sentido Restrito Denso, Corpos d'água, Formações

TABELA 3 - Resultado da análise da exatidão do mapa de cobertura e uso da terra por meio de dados de campo (GPS).

\begin{tabular}{lccc}
\hline \multicolumn{1}{c}{ Classes avaliadas } & Pontos Coletados & $\begin{array}{c}\text { Acurácia do produtor } \\
\text { Acurácia do usuário } \\
\text { (classe) }\end{array}$ & $\begin{array}{c}\text { Exatidão } \\
\text { global }\end{array}$ \\
\hline Agricultura & 47 & $88 \%$ & $93,62 \%$ \\
\hline Cerrado Sentido Restrito Ralo & 8 & $85,71 \%$ & $75 \%$ \\
\hline Cerrado Sentido Restrito Denso & 78 & $93,59 \%$ & $93,6 \%$ \\
\hline Formações Florestais & 11 & $100 \%$ & $90,9 \%$ \\
\hline Floresta Plantada & 5 & $100 \%$ & $100 \%$ \\
\hline Pastagem & 123 & $92,62 \%$ & $91,9 \%$ \\
\hline
\end{tabular}


Florestais, Floresta Plantada, Estradas, Mosaicos de Ocupação, Pastagem e Praias.

Na Tabela 4 estão descritas as áreas ocupadas por cada classe de cobertura e uso da terra analisadas para bacia do Rio do Coco.

Como pode ser observado na Tabela 4, o total das áreas cobertas por usos somam 56,91\%, sendo a classe de pastagem predominante ao longo de toda a bacia, representando $53,37 \%$ do uso total. De acordo com Prado et al. (2012), no geral a pastagem tende a prevalecer, por se tratar de uma atividade mais independente do que a agricultura no que se refere à topografia e à necessidade de escoamento de seus produtos.

É importante ressaltar a importância de trabalhos visando práticas de manejo e conservação do solo nas áreas de pastagem que cobrem a bacia, uma vez que esta atividade ocupa áreas extensas. Dias-Filho (2010) relata que a falta de cuidado reflete na baixa longevidade produtiva do pasto com a formação de vastas áreas degradadas, incentivando o desmatamento para a formação de novas áreas ou, ainda, a expansão das áreas de pastagem nas áreas de vegetação natural.

O problema se torna ainda mais preocupante, pois a ocupação também ocorre nos locais destinados à preservação permanente que são utilizadas como áreas de uso alternativo do solo. Durante a pesquisa pode-se visualizar muitas áreas de pasto adentrando as matas ciliares, resultando em destruição da cobertura vegetal. Souza et al. (2012) citam que qualquer alteração na vegetação ao longo dos rios, por menor que seja, criam instabilidade nas zonas ripárias com consequências sobre toda a estrutura hídrica.

TABELA 4 - Área ocupada por cada classe de cobertura e uso da terra da bacia do Rio do Coco, Tocantins, Brasil.

\begin{tabular}{|c|c|c|}
\hline \multirow{2}{*}{ Cobertura e uso do solo } & \multicolumn{2}{|c|}{ Área total da Bacia Rio do Coco } \\
\hline & (ha) & $(\%)$ \\
\hline Agricultura & $18.298,8$ & 2,90 \\
\hline Área urbana & $2.279,2$ & 0,36 \\
\hline Floresta Plantada & 879,0 & 0,14 \\
\hline Mosaicos de ocupação & 63,6 & 0,01 \\
\hline Pastagem & $336.825,3$ & 53,37 \\
\hline Total de áreas antrópicas & $359.208,8$ & 56,91 \\
\hline Cerrado Sentido Restrito Ralo & $51.936,0$ & 8,23 \\
\hline Formações Florestais & $130.943,0$ & 20,75 \\
\hline Praias & 163,6 & 0,03 \\
\hline Total de áreas naturais & $271.927,7$ & 43,1 \\
\hline Total geral & $631.136,5$ & 100 \\
\hline
\end{tabular}


A atividade agrícola, comparada à pastagem, ainda é pouco significativa, compondo apenas $2,9 \%$ da bacia, principalmente na região oeste, com destaque aos municípios de Marianópolis, Caseara e Chapada de Areia, onde foram observados o avanço desta atividade nos últimos anos. Segundo Prado et al. (2012), neste mercado os locais primeiramente ocupados são aqueles que oferecem a melhor solução na articulação de variáveis como topografia, solos propícios e localização. Tal situação tem sido observada na bacia do Rio do Coco, sendo as áreas mais planas previamente ocupadas, mantendo a pastagem nas regiões com relevo mais ondulado.

A principal cultura implantada é soja, a qual foi bastante observada durante as visitas de campo ao longo da bacia, notadamente nas regiões onde existiam pastos. De acordo com Lima (2014), o baixo preço da terra no Tocantins comparada as áreas mais antigas ou consolidadas da fronteira agrícola no país, além de investimentos em logística e facilidades oferecidas pelo Estado tem atraído muitos agricultores para a região. Frente a isso, percebe-se que, apesar de incipiente, a agricultura tem avançado consideravelmente. Desse modo, nestas regiões há um intenso investimento com obras e insumos visando suprir as necessidades da atividade.

Lima (2014) cita ainda que a soja tem se tornado uma commodity altamente representativa na pauta exportadora do Estado do Tocantins, no entanto, o avanço dessa monocultura é acompanhado da degradação das relações espaciais como aumento expressivo da especulação imobiliária rural, expulsão de pequenos produtores de suas antigas áreas de moradia e produção e crescimento da precarização da mão de obra.

Também estão presentes na bacia as áreas urbanas dos municípios de Caseara, Marianópolis do Tocantins, Divinópolis do Tocantins, Monte Santo, Paraíso do Tocantins e Chapada de Areia, representado um total de 70.369 habitantes (IBGE, 2016). A maior população está localizada no município de Paraíso do Tocantins com 49.727 habitantes (IBGE, 2016), o qual representa grande importância comercial e econômica para a região. Além dessas cidades, existem ainda povoados, vilas, assentamentos, classificados como mosaicos de ocupação que somados as áreas urbanas perfazem um total de $0,37 \%$ da área.

No que tange a classe de floresta plantada, foram identificados durante as atividades de campo, o eucalipto, a seringa e a teca. A classe representa $0,14 \%$ da cobertura identificada na bacia.

Em relação às áreas naturais ainda existentes na região identificaram-se um total de aproximadamente $43,1 \%$, representados pelos corpos d'água, pelas praias e pela cobertura vegetal. Esta, apesar de bastante fragmentada, representa $42,29 \%$ das áreas cobertas com vegetação nativa, destacando-se a classe de Formações Florestais com 20,75\%, onde estão presentes as áreas de mata ciliar, mata de galeria, mata seca e cerradão, as quais estão localizadas, principalmente, ao longo dos cursos d'água e de áreas próximas, onde a disponibilidade de nutrientes e água no solo são os fatores principais para o seu desenvolvimento.

A classe de Cerrado Sentido Restrito Denso representa $13,31 \%$ da cobertura nativa, representando as áreas compostas por cerrado denso e típico. Já a classe de Cerrado Sentido Restrito Ralo compõe $8,23 \%$ das áreas com vegetação, nas quais estão incluídas as fitofisionomias de cerrado ralo e rupestre, parque cerrado, campo sujo e varjão.

A classe de corpos d'água corresponde $0,78 \%$ da bacia, sendo composta por rios, ribeirões, cór- 
regos, lagos, lagoas e represas. Os rios principais são o Rio do Coco, o Ribeirão Piedade, o Ribeirão Surubim e o Ribeirão Prata. A área também conta com inúmeras represas distribuídas por toda bacia, nas quais prevalecem o uso para atividade agropecuária, que é dominante na região. Além das represas, estão presentes lagos e lagoas naturais, principalmente nas áreas próximas as planícies dos principais cursos d'água.

Não menos importante, destaca-se a classe de praias, que apesar de bastante reduzida $(0,03 \%)$ estão presentes nas margens dos cursos d'água, especialmente, ao longo do Rio do Coco. Estas sofrem grande influência da sazonalidade, sendo expostas, em sua maioria, no período de estiagem. A grande oscilação no nível dos corpos hídricos é uma característica da região, fazendo com que nos meses mais secos haja a exposição de bancos de areias ou até mesmo o aparecimento de ilhas no meio dos canais de drenagem.

$\mathrm{Na}$ Figura 4 pode ser observada a distribuição da cobertura e uso da terra da bacia hidrográfica do

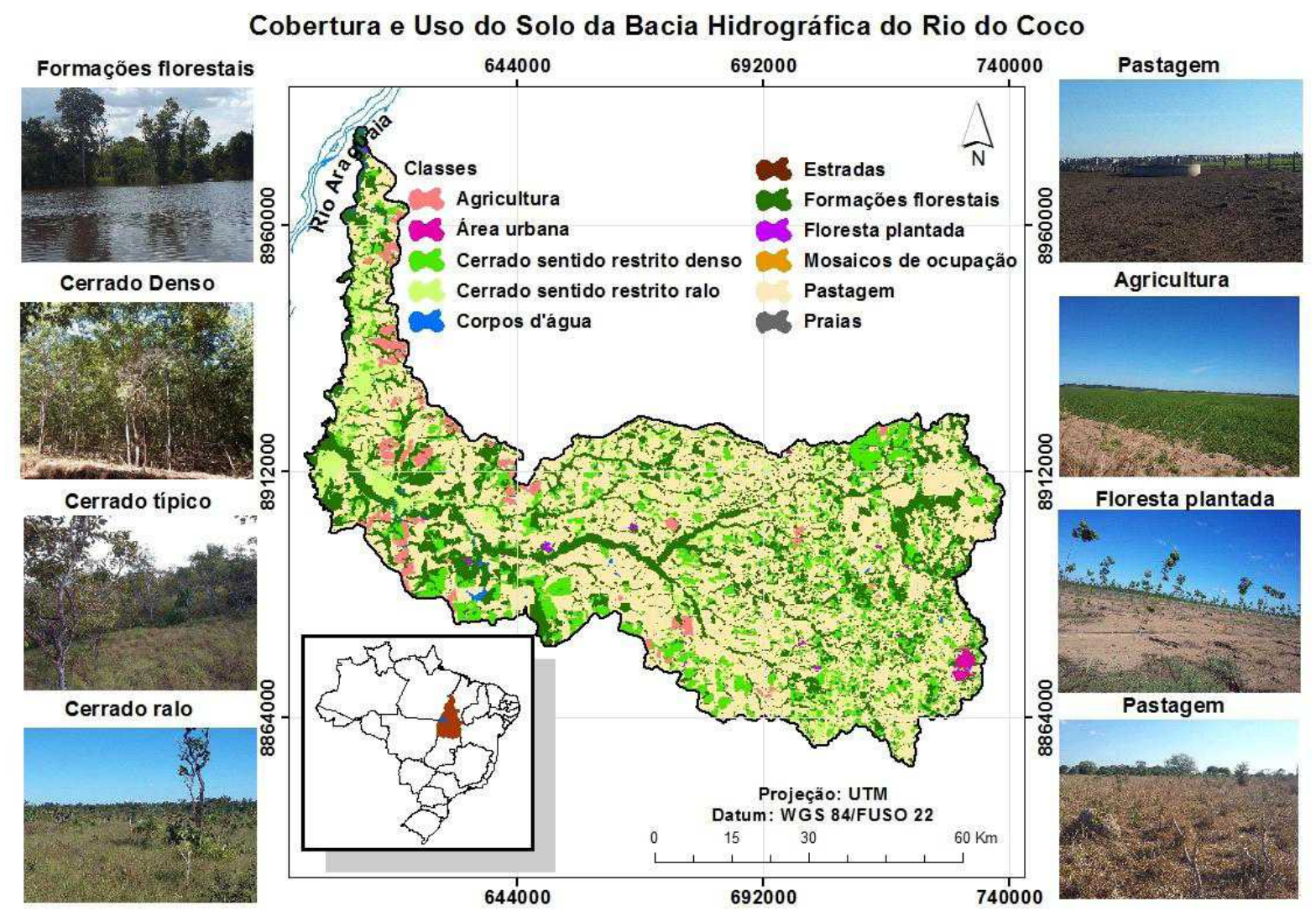

FIGURA 4 - Cobertura e uso da terra da bacia do Rio do Coco, Tocantins, Brasil, com destaque para as principais formas de ocorrência das classes de uso identificadas.

FONTE: Elaborado pelo autor. 
Rio do Coco. Nela fica evidente o predomínio da classe de pastagem sobre as demais classes analisadas. Observa-se também a agricultura sendo implantada, especialmente nas regiões com relevo mais favorável, além de mostrar a arranjo da vegetação ainda existente em toda a bacia.

\subsection{Cobertura e uso da terra nos compartimentos da bacia do Rio do Coco}

Como pode ser observado na Figura 5, na Alta bacia estão localizadas as sub-bacias do Ribeirão Piedade, Alto Rio do Coco e Ribeirão Surubim, todas de ordem 6. Já na região da Baixa bacia encontram-se as sub-bacias do Ribeirão Prata e Baixo Rio do Coco, 5 e 7 ordem, consecutivamente.

$\mathrm{Na}$ Tabela 5 podem ser observados os percentuais de cobertura e uso da terra nos compartimentos da bacia hidrográfica do Rio do Coco.

O compartimento da alta bacia do Rio do Coco, representado pelas sub-bacias do Alto Rio do Coco, Ribeirão Piedade e Ribeirão Surubim, apresentou $60,07 \%$ de áreas cobertas por algum tipo de uso, tendo o compartimento da baixa bacia do Rio do Coco (Baixo Rio do Coco e Ribeirão Prata) um percentual de $53,45 \%$. Este maior percentual de áreas antropizadas no compartimento da alta bacia

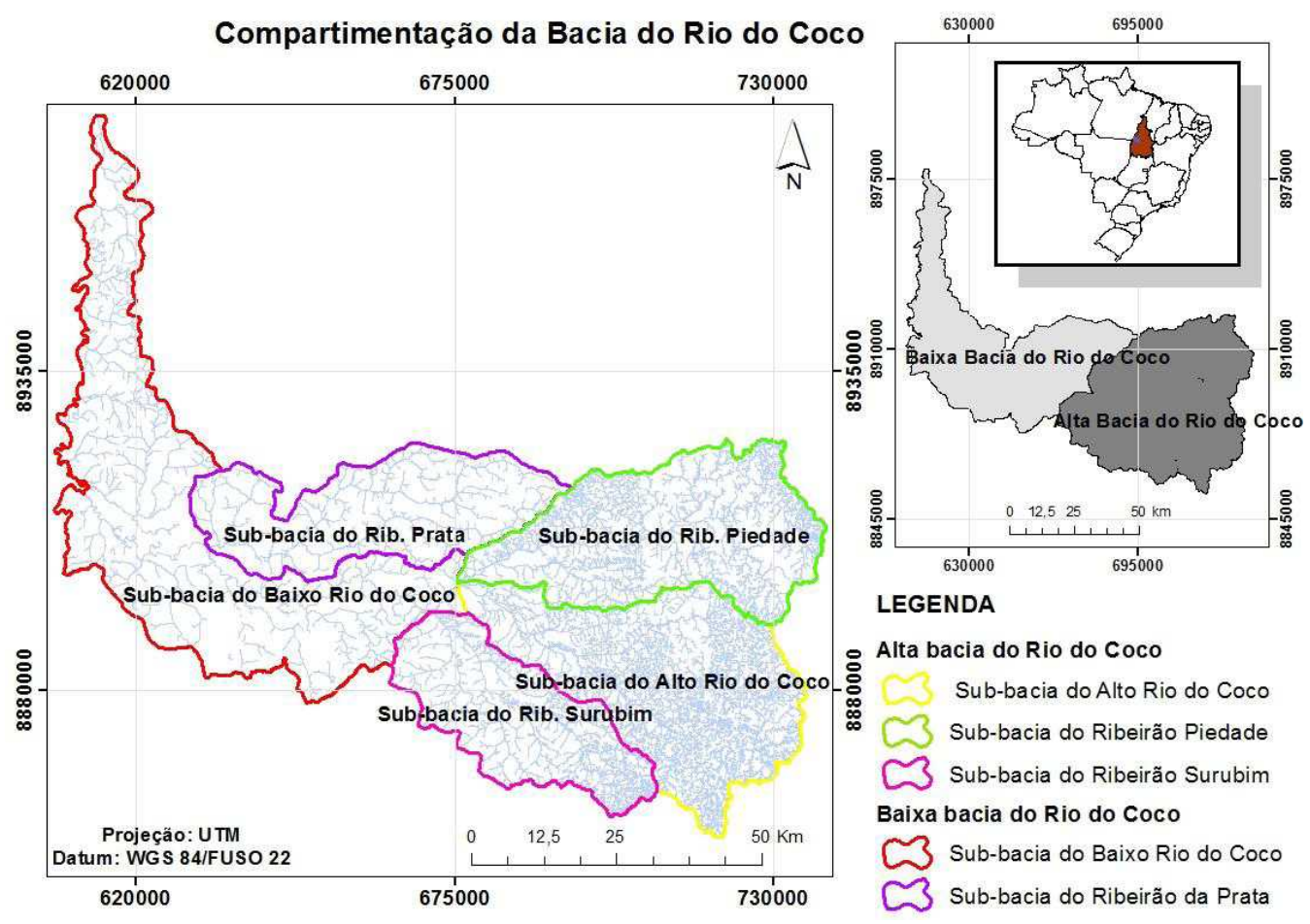

FIGURA 5 - Sub-bacias presentes nos compartimentos da Alta e Baixa Bacia do Rio do Coco, Tocantins, Brasil.

FONTE: Elaborado pelos autores. 
pode estar relacionado com o processo de desenvolvimento da região, como a maior proximidade de áreas urbanas importantes e como a disponibilidade de infraestrutura (estradas para a circulação de bens e serviços).

Um ponto importante que merece ser destacado trata-se da criação do Estado do Tocantins e da construção da BR 153, tais atividades além de proporcionarem a criação e o desenvolvimento de algumas cidades importantes, como o caso de Paraíso do Tocantins (construída as margens da rodovia), conduziram ao aumento da população local e a consolidação de alguns aglomerados populacionais já existentes. Desse modo, pressupõe-se que todo esse processo de desenvolvimento proporcionou a abertura de áreas naturais para a implantação de diversas atividades, com destaque para a pastagem que se expandiu rapidamente na região.

No compartimento que compreende a baixa bacia do Rio do Coco o desmatamento e a implantação das atividades de uso do solo ocorreram mais lentamente, conforme o mapeamento de uso do

TABELA 5 - Quantificação da área ocupada por cada classe de cobertura e uso da terra nos compartimentos da bacia do Rio do Coco, Tocantins, Brasil.

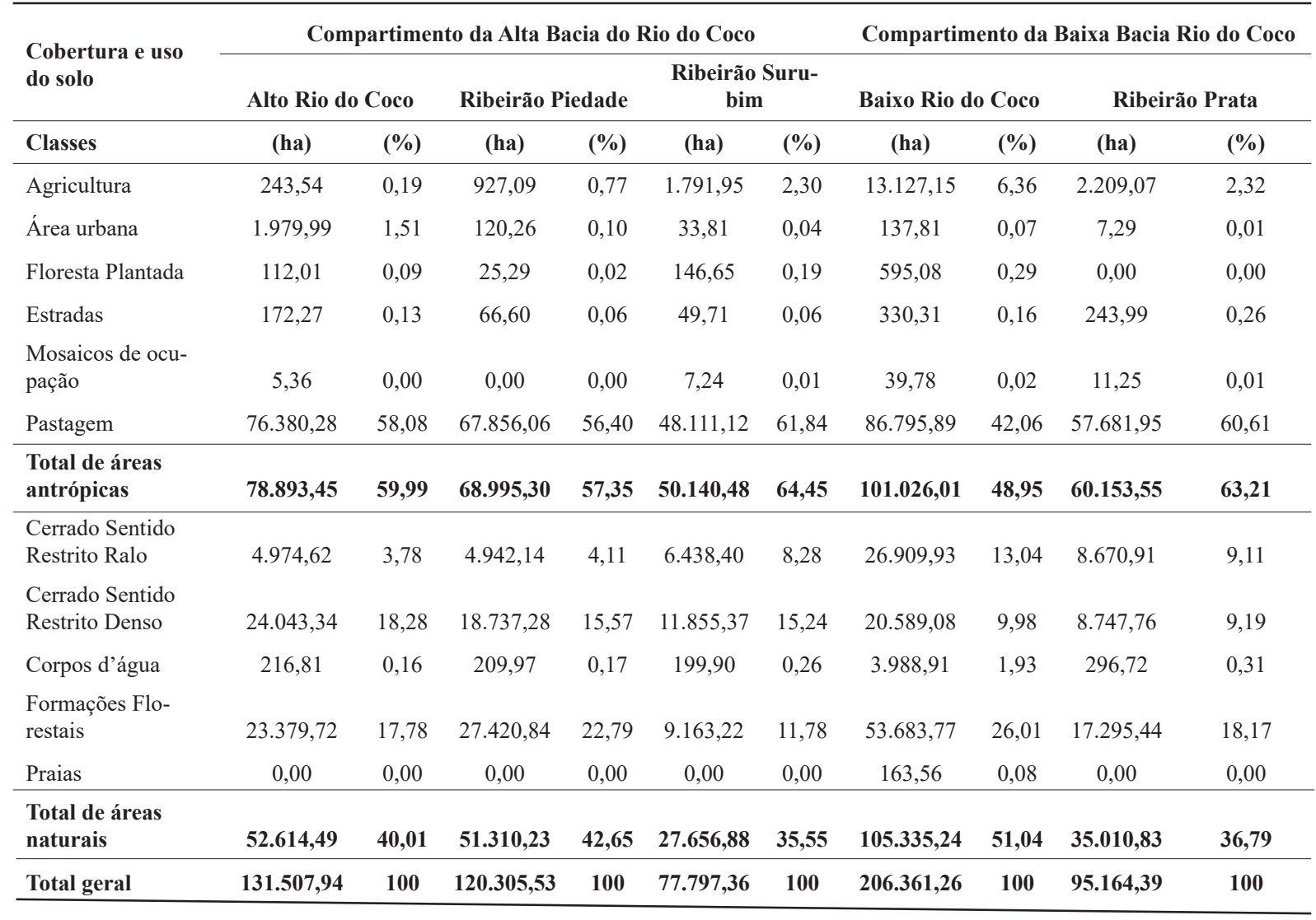


solo realizado. Uma das justificativas são a maior distância dos aglomerados urbanos mais desenvolvidos e a escassa disponibilidade de estradas e infra-estrutura. Além dos fatores relatados, há de se destacar a presença das unidades de conservação locais (Parque Estadual do Cantão e a APA Ilha do Bananal/Cantão), as quais podem ter inibido o processo de desenvolvimento comparado ao verificado na alta bacia, pois, cabe mencionar, que todo o compartimento da baixa bacia está inserido nas unidades de conservação citadas.

Especificamente em relação às sub-bacias, observa-se que praticamente todas se encontram com atividades de uso acima de $50 \%$, exceto a sub-bacia do Baixo Rio do Coco que totalizou $48,95 \%$ de atividades antrópicas. Em se tratando de áreas com maiores percentuais de uso do solo, as sub-bacias do Ribeirão Surubim e Ribeirão Prata apresentaram resultados semelhantes, com $64,45 \%$ e $63,21 \%$, consecutivamente.

No caso da sub-bacia do Alto Rio do Coco, foram mapeadas $59,99 \%$ de áreas antrópicas e $40,01 \%$ de áreas naturais. O uso com a pastagem teve destaque com $58,08 \%$, seguido pela área urbana com 1,51\%, representando o município de Paraíso do Tocantins. Já em relação às áreas naturais, o Cerrado Sentido Restrito Denso se sobrepõe com 18,28\%, seguido pela classe de Formações Florestais $17,78 \%$.

Para a sub-bacia do Ribeirão Piedade observou-se $57,35 \%$ de uso antrópico e $42,65 \%$ de áreas naturais. A pastagem nesta região também predominou com $56,4 \%$, seguido por $0,77 \%$ de agricultura. As classes de cobertura vegetal dominantes são as Formações Florestais com 22,79\% e Cerrado Sentido Restrito Denso com 15,57\%.
A sub-bacia do Baixo Rio do Coco apresentou $48,95 \%$ de sua área com uso contra $51,04 \%$ com áreas naturais. Em relação ao uso, a pastagem se sobressai com $42,06 \%$, seguida pela agricultura com $6,36 \%$. Por outro lado, as áreas naturais se destacam com 26,01\% de Formações Florestais, 13,04\% de Cerrado Sentido Restrito Ralo e 9,98\% de Cerrado Sentido Restrito Denso.

No geral, pode-se considerar a pastagem como atividade dominante em comparação com as outras classes de uso, se sobrepondo em todas as regiões, principalmente, nas sub-bacias do Ribeirão Surubim com $61,84 \%$, Ribeirão Prata $60,61 \%$, Alto Rio do Coco 58,08\% e Ribeirão Piedade 56,4\%. Já a agricultura, apesar de incipiente, tem avançado bastante nos últimos anos nas áreas que abrangem as sub-bacias do Baixo Rio do Coco (6,36\%), Ribeirão Prata $(2,32 \%)$ e Ribeirão Surubim (2,3\%).

$\mathrm{O}$ predomínio da pastagem em relação às outras atividades tem ligação com o histórico de ocupação do Estado. Lima (2014) ressalta que no Tocantins, a pecuária é uma atividade que indiscutivelmente acompanhou a formação do espaço para a entrada do capital. Desde a abertura de caminhos nas matas e cerrados à espoliação e especulação de terras pelas elites que lideraram os movimentos de separação do estado de Goiás.

A prevalência da pastagem em bacias hidrográficas é também comumente encontrada em outros estudos de cobertura e uso da terra ao longo do país. Nunes et al. (2015), ao realizarem pesquisas em uma microbacia no município de Alta Floresta (MT), observaram que $54,6 \%$ das áreas possuíam conflito de uso, sendo destas $47,7 \%$ representado pela pastagem. 
4.4. Conflitos de uso nas áreas de preservação permanente

A Figura 6 apresenta uma análise dos conflitos de uso existente em relação às áreas de preservação permanente de cursos d'água da bacia hidrográfica do Rio do Coco e de suas sub-bacias. Nela é possível observar o percentual de APP preservada ainda presente para cada bacia e as áreas com presença de uso.

De acordo com a Figura 6, a bacia do Rio do Coco apresenta 32,8\% de áreas com conflitos de uso em APP, sendo destes 32,37\% representados pelos conflitos com a pastagem. Resultados semelhantes também foram encontrados por Pinto et al. (2011) após estudos em áreas de preservação permanente nas cabeceiras do Alto Rio Paraguai, onde foram identificados $36,85 \%$ de áreas com conflitos de uso em APP e por Silva et al. (2016) na bacia do Ribeirão dos Pinheirinhos em Brotas (SP) com $32,09 \%$ das APPs ocupadas com alguma atividade irregular. Nos estudos citados, as irregularidades foram representadas, principalmente, pela pastagem e agricultura.

O cenário apresentado é preocupante, especialmente, por ocuparem áreas destinadas à preservação. Segundo Rodrigues et al. (2015a), as áreas marginais de proteção dos rios são importantes elementos para a preservação e estabilidade do regime fluvial. Desse modo, a exposição do solo causada pela remoção da cobertura vegetal pode levar a compactação, que contribui para a diminuição da porosidade e da permeabilidade do solo, provocando a diminuição na retenção de

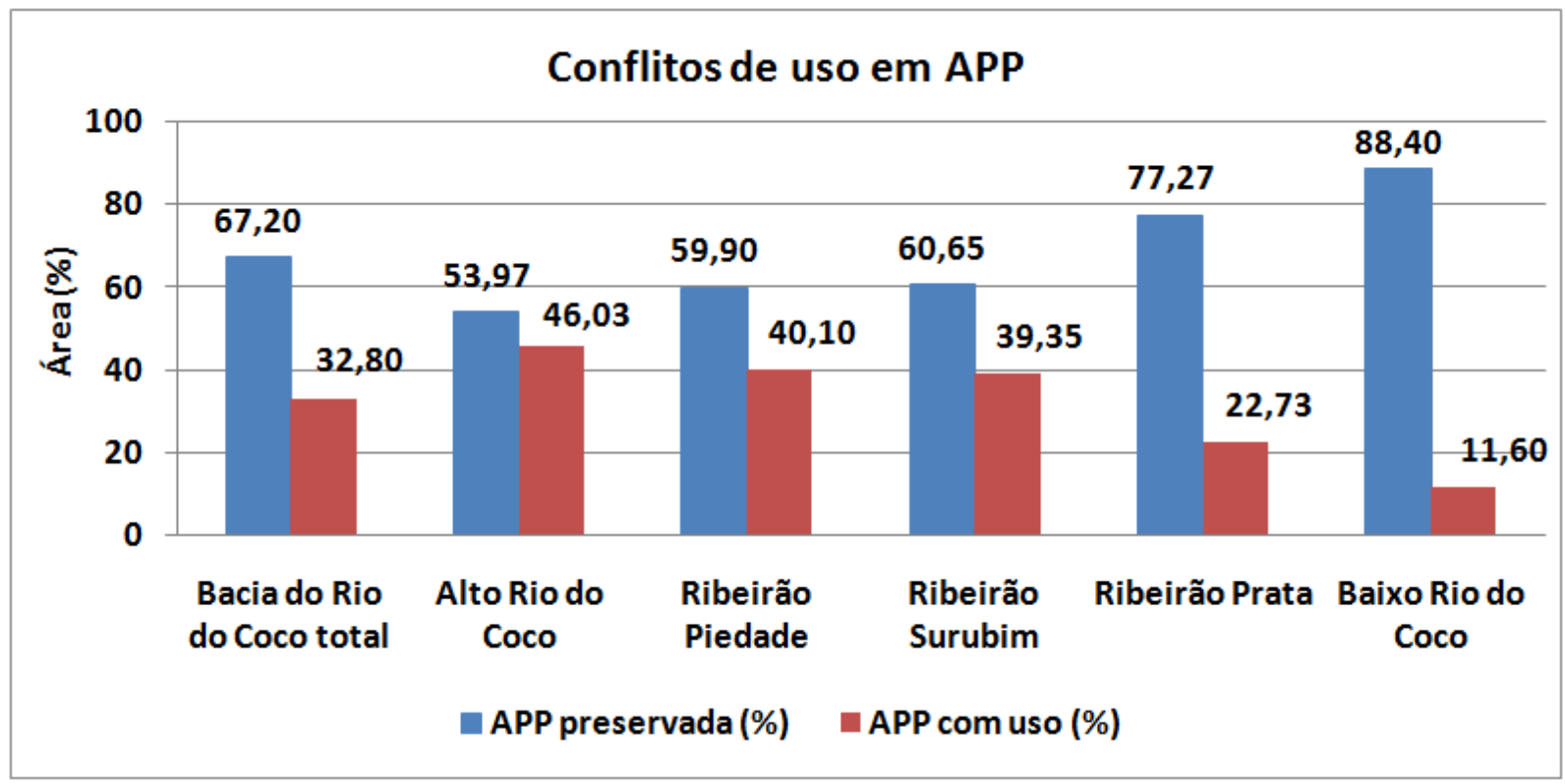

FIGURA 6 - Conflitos de uso em Áreas de Preservação Permanente (APP) nas principais sub-bacias da bacia do Rio do Coco, Tocantins, Brasil. 
água e, por conseguinte, o assoreamento dos corpos d'água locais (Gonçalves et al., 2016). Durante a classificação observou-se um número elevado de cursos d'água com suas respectivas faixas de APPs totalmente destruídas pelos diversos tipos de usos desenvolvidos na região. Tal situação tende a potencializar a capacidade de produção de sedimentos na bacia, uma vez que pode haver constantes perdas de solos por erosão.

Quando se analisa separadamente as sub-bacias, conclui-se que os conflitos de uso da terra atingem percentuais variados, chegando até $46,03 \%$, conforme apresentado para o Alto Rio do Coco, a qual apresentou maior percentual de uso em APP, seguido pelas sub-bacias dos Ribeirões Piedade e Surubim com $40,1 \%$ e $39,35 \%$, consecutivamente. Tais resultados confirmam o processo histórico de ocupação na região da alta bacia.

Em relação às demais áreas analisadas, a sub-bacia do Baixo Rio do Coco foi a que apresentou menor conflito em APP, com 11,6\%, seguido pela sub-bacia do Ribeirão Prata com 22,73\%.

No geral, o grupo de sub-bacias pertencentes ao compartimento da alta bacia do Rio do Coco apresentou mais uso em áreas de preservação permanente comparado as sub-bacias do compartimento da baixa bacia do Rio do Coco. Por sua vez, os resultados encontrados indicam uma ligação com o processo de uso e ocupação das terras na região, influenciados, principalmente, pela atividade agropecuária. Por outro lado, é interessante destacar também que o sistema de drenagem das bacias analisadas podem também ter influenciado nos resultados. A alta bacia possui maior número de canais por área e, consequentemente necessita de mais áreas destinadas a APP.
A Figura 7 mostra os conflitos de uso da terra identificados para as áreas de preservação permanente nas sub-bacias da bacia do Rio do Coco.

Conforme demonstrado na Figura 7, as sub-bacias da alta bacia do Rio do Coco (Alto Rio do Coco, Ribeirão Piedade e Ribeirão Surubim) possuem uma densidade de drenagem mais desenvolvida em relação às sub-bacias da baixa bacia do Rio do Coco (Baixo Rio do Coco e Ribeirão Prata). Essa assertiva pode ser confirmada pelos resultados obtidos por Almeida et al. (2016) em estudos morfométricos realizados na bacia hidrográfica do Rio do Coco, a qual foi subdividida quanto a sua drenagem em: a) bem drenada - sub-bacia do Alto Rio Coco $(2,104$ $\mathrm{km} / \mathrm{km}^{2}$ ); b) drenagem média - sub-bacias do Ribeirão Piedade $\left(1,55 \mathrm{~km} / \mathrm{km}^{2}\right)$ e Ribeirão Surubim $\left(1,321 \mathrm{~km} / \mathrm{km}^{2}\right)$ e c) drenagem pobre - sub-bacias do Ribeirão Prata $\left(0,62 \mathrm{~km} / \mathrm{km}^{2}\right)$ e Baixo Rio Coco $\left(0,636 \mathrm{~km} / \mathrm{km}^{2}\right)$.

Por sua vez, o elevado conflito de uso em de APP para o compartimento da alta bacia (Alto Rio do Coco, Ribeirão Piedade e Surubim) sugere uma relação com o maior número de canais de primeira ordem. No geral, dentro do contexto histórico de ocupação do solo em propriedades rurais é dada pouca importância a estes canais, os quais, na maioria das vezes, são degradados pelo avanço das atividades antrópicas nas áreas destinadas a proteção.

Freitas et al. (2013) chamam a atenção em relação as práticas de ocupação em canais de ordens inferiores, pois estas são áreas muito sensíveis e, em sua grande maioria, estão localizadas em relevo acidentado, com maior suscetibilidade aos processos erosivos. Os autores, ao realizarem estudos na bacia hidrográfica do Rio Jundiaí-Mirim, constataram a presença de $55,4 \%$ de ocupações irregulares em APPs, centralizadas, principalmente nestes canais, 
concluindo que a concentração de usos nessas regiões tende a potencializar os impactos gerados em toda a bacia.

Outro aspecto que merece atenção em relação aos conflitos existentes nas áreas de preservação permanente refere-se a não garantia de recuperação das áreas degradadas pela legislação ambiental. A Lei $\mathrm{n}^{\circ}$. 12.651/2012 trouxe grandes mudanças nos processos de recuperação destas, pois desobriga as propriedades rurais que possuem área rural conso- lidada em APP de recuperarem a largura mínima exigida para o curso d'água, sendo a recuperação definida de acordo com o tamanho do imóvel e não de acordo com a largura do corpo hídrico.

Soares-Filho et al. (2014) estimam uma redução de $22 \%$ dos passivos ambientais com áreas de preservação permanente em função das novas regras impostas pelo Código Florestal. Almeida \& Vieira (2014) constataram essa realidade ao analisarem 608 propriedades com CAR no município de Mo-
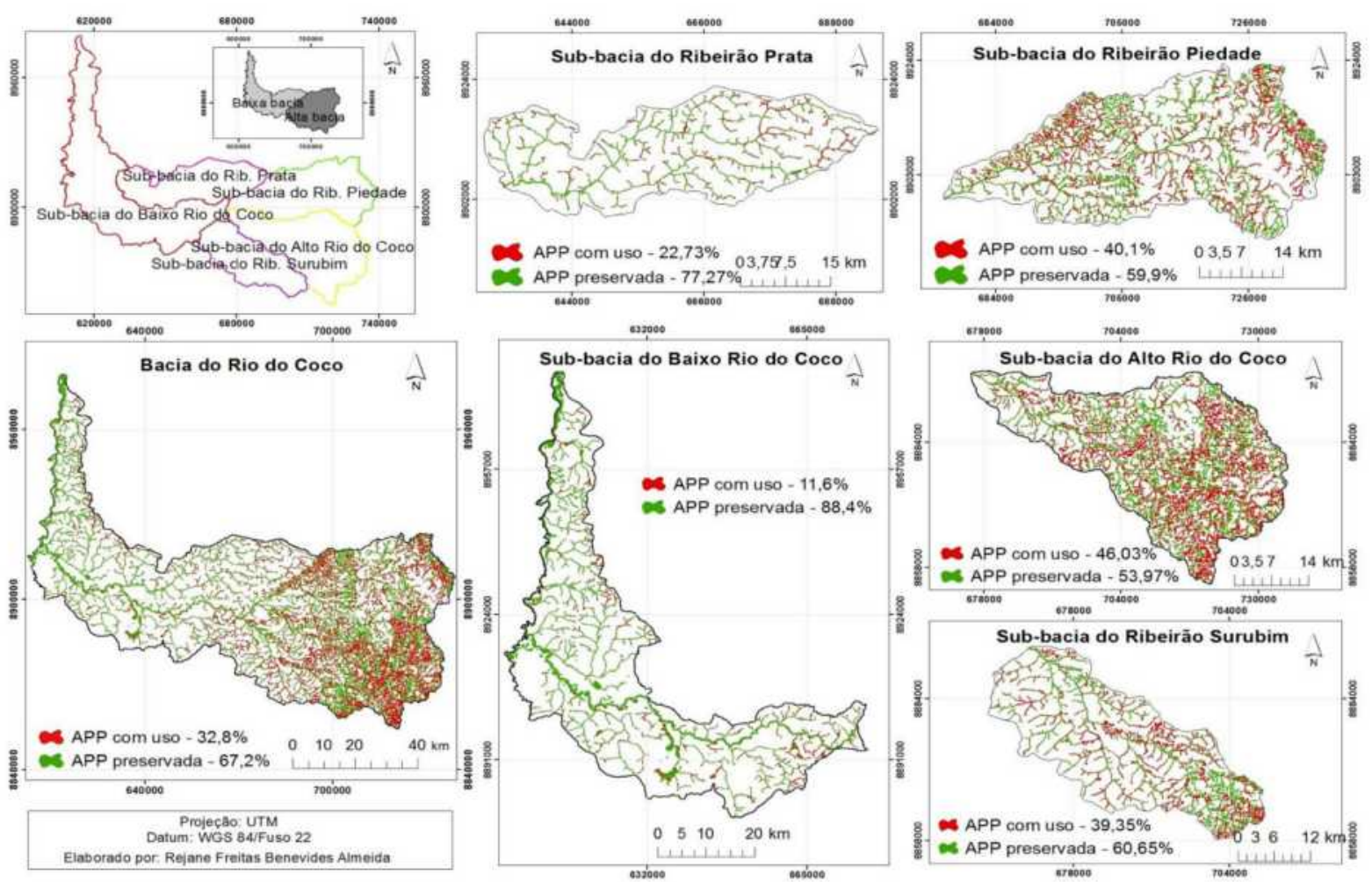

FIGURA 7 - Conflitos de uso da terra nas áreas de preservação permanente nas sub-bacias do Rio do Coco, Tocantins, Brasil. FONTE: Elaborado pelo autor 
ju (PA), onde observaram 9.202,21 ha de passivo ambiental em APPs, entretanto, destes, somente 3.617,21 ha estão sujeitas à recomposição, ou seja, haverá uma perda de $60,69 \%$ da área total de APPs nessas propriedades, que legalmente deixarão de ser restauradas com a aplicação do novo código florestal, uma vez que muitos usos existentes são considerados consolidados. Nesta perspectiva, Siqueira et al. (2016), ao estudarem os aspectos ecológicos da vegetação lenhosa em áreas de preservação permanente, observaram que a presença de áreas consolidadas podem trazer alterações na estrutura e funcionamento das APPs existentes no Brasil com perdas significativas de espécies e indivíduos, fazendo com que estas áreas deixem de cumprir as funções ambientais previstas na legislação.

Tendo em vista as discussões aqui apresentadas, faz-se necessário o estabelecimento de um planejamento ambiental e territorial eficiente, voltado, principalmente, para a efetiva proteção e conservação das áreas legalmente protegidas, de modo a garantir a manutenção da qualidade ambiental de toda a bacia, uma vez que as práticas inadequadas de uso e ocupação do solo têm efeitos negativos sobre todo o sistema hidrográfico.

\section{Conclusões}

Os resultados da análise da cobertura e uso da terra da bacia hidrográfica do Rio do Coco e suas implicações sobre as áreas de preservação permanente permitem concluir que:

- A bacia do Rio do Coco apresenta 56,91\% de sua área total coberta por usos antrópicos, sendo a pastagem o uso predominante, com 53,37\%. Tal fato sugere grande relação com os processos de ocupação na região sendo esta atividade, comparada às demais, com menor dependência topográfica e insumos;

- A atividade agrícola, embora ainda incipiente, representa $2,9 \%$ do uso na bacia. Esta tem avançado nos últimos anos, ocupando as áreas mais planas, especialmente nos municípios de Marianópolis, Caseara e Chapada de Areia, mantendo a pastagem nas regiões com relevo mais ondulado;

- Há ainda na bacia 43,1\% de áreas naturais, representados pelos corpos d'água, pelas praias e pela cobertura vegetal, sendo a classe de Formações Florestais prevalecente, cobrindo $20,75 \%$ da área total da bacia;

- A maioria das sub-bacias analisadas encontra-se com atividades de uso acima de $50 \%$, com destaque para as sub-bacias dos Ribeirões Surubim e Prata que apresentaram maiores percentuais de uso do solo com $64,45 \%$ e $63,21 \%$, respectivamente;

- A pastagem também se sobrepôs como atividade dominante nas sub-bacias avaliadas, com destaque para o Ribeirão Surubim com 61,84\%, Ribeirão Prata $60,61 \%$, Alto Rio do Coco $58,08 \%$ e Ribeirão Piedade $56,4 \%$;

- Foi verificado $32,8 \%$ de conflitos de uso em áreas de preservação permanente de cursos d'água em toda a bacia do Rio do Coco, sendo destes $32,37 \%$ representados pelos conflitos com a pastagem;

- Comparativamente as demais sub-bacias analisadas, a sub-bacia do Alto Rio do Coco apresentou maior percentual de 
conflitos em APP (46,03\%), seguido pelas sub-bacias dos Ribeirões Piedade, Surubim, Prata e Baixo Rio do Coco com $40,1 \%, 39,35 \%, 22,73 \%$ e $11,6 \%$, consecutivamente. Tais resultados tendem a potencializar a ocorrência de processos erosivos e, por conseguinte influenciar no volume de sedimentos entregues por estas bacias;

- Os elevados percentuais de conflito para as áreas de preservação permanente de cursos d'água nas sub-bacias em estudo indicam ligação com as formas de uso e ocupação das terras na região, influenciados, principalmente, pela atividade agropecuária;

- Os maiores impactos sentidos pelas sub-bacias do compartimento da alta bacia do Rio do Coco (Alto Rio do Coco, Ribeirão Piedade e Surubim) sugerem grande relação com o sistema de drenagem destas, principalmente, pelo elevado número de canais de ordens inferiores, os quais, em sua maioria, são primeiramente degradados pelas atividades antrópicas;

- A flexibilização da legislação ambiental vigente, no que diz respeito à manutenção de áreas consolidadas em APPs tende agravar o quadro de degradação ambiental apresentado para a bacia do Rio do Coco e suas sub-bacias com efeitos diretos sobre a qualidade ambiental de todo o sistema.

Por fim, o estudo da cobertura e uso da terra da bacia do Rio do Coco utilizando o geoprocessamento como ferramenta de análise mostrou-se relativamente eficiente no que diz respeito à identificação e quantificação de áreas naturais e antrópicas, bem como na quantificação dos conflitos de uso existentes em relação às áreas de preservação permanente de cursos d'água, sendo possível, desse modo, compreender a distribuição dos usos em toda a bacia e de que forma os mesmos tem afetado as áreas legalmente protegidas, contribuindo para uma análise mais apropriada dos recursos hídricos, que é de fundamental importância nos processos de gestão.

\section{Referências}

Almeida, R. F. B.; Bayer, M.; Ferreira Júnior, L. G. Compartimentação morfométrica da Bacia do Rio do Coco como subsídio a análise de fragilidade ambiental. Mercator, Fortaleza, 15, 4, 88, 2016.

Almeida, A. S.; Vieira, I. C. G. Conflitos no uso da terra em Áreas de Preservação Permanente em um pólo de produção de biodiesel no Estado do Pará. Revista Ambiente \& Água, 9, 484-485, 2014.

Aparecido, C. F. F.; Vanzela, L. S.; Vazquez, G. H.; Lima, R. C. Manejo de bacias hidrográficas e sua influência sobre os recursos hídricos. Irriga, 21, 241-250, 2016.

Aquino, S.; Stevaux, J. C.; Latrubesse, E. M. Regime hidrológico e aspectos do comportamento morfohidráulico do Rio Araguaia. Revista Brasileira de Geomorfologia, 2, 31, 2005.

Brasil. Lei $n^{\circ}$. 12.651 de 25 de maio de 2012. Dispõe sobre a proteção da vegetação nativa.

Brasil. Resolução Conama $n^{\circ}$. 302/2002, de 20 de março de 2002. Dispõe sobre os parâmetros, definições e limites de áreas de preservação permanente de reservatórios artificiais e o regime de uso do entorno.

Brasil. Ministério do Meio Ambiente. Instituto Nacional de Pesquisas Espaciais (INPE). Projeto TerraClass Cerrado. Mapeamento do Uso e Cobertura Vegetal do Cerrado. Disponível em: http://www.dpi.inpe.br/tccerrado/. Acesso em: 10 de fevereiro de 2018.

Campos, S.; Silveira, G. R. P. da; Pissarra, T. C. T.; Felipe, A. C.; Garcia, Y. M.; Campos, M. Diagnóstico do uso do 
solo em APP na microbacia do Córrego Santo Antonio - São Manuel (SP) em função da legislação ambiental. Revista Eletrônica Geoaraguaia, 3, 200, 2013.

Congalton, R. G. Thematic and Positional Accuracy Assessment of Digital Remotely Sensed Data. In: Proceedings of the Seventh Annual Forest Inventory and Analysis Symposium. Portland, ME, October, 2005. p. 150.

Dias-Filho, M. B. Produção de bovinos a pasto na fronteira agrícola. In: Rodrigues, K. F.; Ferreira, W. M.; Macedo Jr, G. de L. (Org.). In: Anais do XX Congresso Brasileiro de Zootecnia. Palmas (TO), 2010. p. 132 e 135.

Ferreira, E.; Zuanon, J.; Santos, G.; Amadio, S. A ictiofauna do Parque Estadual do Cantão, Estado do Tocantins, Brasil. Biota Neotropica, 11, 278-279, 2011.

Freitas, E. P.; Moraes, J. F. L. de; Peche Filho, A.; Storino, M. Indicadores ambientais para áreas de preservação permanente. Revista Brasileira de Engenharia Agrícola e Ambiental, 17, 445-448, 2013.

Gonçalves, D. S; Souza, P. A. de; Oliveira, A. L. de; Martins, T. S. Diagnóstico ambiental e proposta de plano de recuperação da APP, Fazenda Santa Juliana, Cariri do Tocantins - TO. Nucleus, 13, 268, 2016.

Gurnell, A. M.; Bussettini, M.; Camenen, B.; Del Tánago, M. G.; Grabowski, R. C.; Hendriks, D.; Henshaw, A.; Latapie, A.; Rinaldi, M.; Surian, N. A hierarchical multiscale framework and indicators of hydromorphological processes and forms. Deliverable 2.1, Part 1, of REFORM (REstoring rivers FOR effective catchment Management), a Collaborative project (large-scale integrating project) funded by the European Commission within the 7th Framework Programme under Grant Agreement, 2014, 102 p.

IBGE - Instituto Brasileiro de Geografia E Estatística. Estimativas da população residente nos municípios brasileiros com data de referência em $1^{\circ}$ de julho de 2016. Disponível em: http://www.ibge.gov.br/home/estatistica/populacao/estimativa2016/estimativa. Acesso em: 26 de outubro de 2016.

Lima, D. A. A expansão da soja na fronteira agrícola moderna e as transformações do espaço agrário tocantinense. 40, 42, 68 e 141 f. Dissertação (Mestrado em Geografia) - Unicamp/Instituto de Geociências. Campinas (SP), 2014.
Nunes, E. J. da S.; Silva, E. P. da; Souza, E. de; Rocha Filho, J. A. da; Silva, D. S. N. da. Geotecnologias no diagnóstico de conflitos de uso do solo de uma microbacia do município de Alta Floresta - MT. Ciência Florestal, 25, 695, 2015.

Pereira, N. S.; Silva, N. C. da; Carvalho Júnior, O. A. de; Silva, S. D. A Importância do Geoprocessamento para a História e o Saber Ambiental. Fronteiras: Journal of Social, Technological and Environmental Science, 3(2), 133, 2014.

Pinto, C. E. T.; Curvo, R. J. de C.; Rossete, A. N.; Vieira, L. R.. Conflitos ambientais em áreas de preservação permanente nas cabeceiras do Alto rio Paraguai em Diamantino/ MT e Alto Paraguai/MT - Brasil. In: Anais do XV Simpósio Brasileiro de Sensoriamento Remoto - SBSR. Curitiba (PR), 30 de abril a 05 de maio de 2011. p. 6.222.

Prado, L. de A.; Miziara, F.; Ferreira, M. E. Expansão da fronteira agrícola e mudanças no uso do solo na região Sul de Goiás: ação antrópica e características naturais do espaço. Boletim Goiano de Geografia, 32, 153-164, 2012.

Prina, B. Z.; Trentin, R. GMC: Geração de Matriz de Confusão a partir de uma classificação digital de imagem do ArcGIS. In: Anais do XVII Simpósio Brasileiro de Sensoriamento Remoto - SBSR. João Pessoa (PB), 25 a 29 de abril de 2015. p. 137.

Rodrigues, A. da. C.; Garcia, P, H. M.; Pinto, A. L. Diagnóstico da composição ripária na bacia hidrográfica do Córrego Taboca, no município de Três Lagoas - MS - 2014. Revista Eletrônica da Associação dos Geógrafos Brasileiros, 22, 179, 2015a.

Rodrigues, A. J. et al. Diagnóstico ambiental de um trecho da área de preservação permanente (APP), margens do Córrego Pouso do Meio, em Gurupi - TO. Enciclopédia Biosfera, 11, 3, 108, 2015 b.

Romero, F. I.; Cozano, M. A.; Gangas, R. A.; Naulim, P. I. Zonas ribereñas: protección, restauración y contexto legal en Chile. Bosque, 35(1), 11. 2014.

Rouse, J. W.; Haas, R. H.; Schell, J. A.; Deering, D. W. Monitoring vegetation systems in the great plains with ERTS. In: Earth resources technology sattelite-1 symposium, 1973, Washington. Proceedings. Washington: 1973. p. 309-317.

Silva, G. C. M.; Costa Júnior, N. P.; Silva, F. M. Caracteri- 
zação do uso da terra no município de Areia Branca - RN, por técnicas de sensoriamento remoto. São Paulo, UNESP, Geociências, 33, 315, 2014.

Silva, J. L.; Tonello, K. C.; Valente, R. A.; Mingoti, R. Diagnóstico ambiental como subsídio à restauração florestal e manutenção hidrológica da Bacia do Ribeirão dos Pinheirinhos, Brotas - SP. Irriga, 21, 08, 2016.

Siqueira, M. N.; Morais, A. R.; Faria, K. M. da S.; Castro, S. S. Ecological aspects related to ligneous vegetation in the permanent preservation areas of Mineiros, Goiás, in light of the new native vegetation protection policy - Law 12.651/2012. Revista Arvore, 40, 581, 2016.

Soares-Filho, B.; Rajão, R.; Macedo, M.; Carneiro, A.; Costa, W.; Coe, M.; Rodrigues, H.; Alencar, A. Cracking Brazil's Forest Code. Science, 363, 363, 2014.

Sousa, S. B. de; Ferreira, L. G. Mapeamento da cobertura e uso da terra: uma abordagem utilizando dados de sensoriamento remoto óptico multitemporais e provenientes de múltiplas plataformas. Revista Brasileira de Cartografia, 66, 329, 2014.
Souza, S. R.; Maciel, M. de N. M.; Oliveira, F. de A.; Jesuíno, S. de A. Caracterização do conflito de uso e ocupação do solo nas áreas de preservação permanente do Rio Apeú, nordeste do Pará. Floresta, 42, 705, 2012.

Strahler, A. N. Hypsometric (area-altitude) analysis and erosional topography. Geological Society of America Bulletin, 63, 1117-1142, 1952.

Tocantins. Secretaria de Planejamento do Estado do Tocantins (Seplan). Base da Dinâmica da Cobertura e Uso da Terra do Tocantins 2007. Disponível em: https://seplan. to.gov.br/zoneamento/bases-vetoriais/base-da-dinamica-da-cobertura-e-uso-da-terra-do-tocantins---199020002007/. Acesso em: 15 de novembro de 2017.

Vargas, R. R.; SAAD, A. R.; Dalmas, F. B.; Rosa, A.; Arruda, R. de O. M.; Mesquita, M. V.; Andrade, M. R. M. de. Water Quality Assessment in the Córrego Taquara do Reino Hydrographic Basin, Guarulhos Municipality (São Paulo State - Brazil): Effects of Environmental Degradation. Anuário do Instituto de Geociências-UFRJ, 38, 138. 2015.

Zanata, M.; Pissarra, T. C. T.; Ferraudo, A. S.; Ranzini, M.; Campos, S. Effect of soil use on the quality of water resource in watershed using multivariate statistical analysis. Irriga, 20, 787, 2015. 